\title{
PEMIKIRAN EKONOMI SAYYID QUTB
}

\author{
Havis Aravik \\ Perbankan Syariah STEBIS IGM Palembang \\ Email : havis@stebisigm.ac.id
}

\begin{abstract}
ABSTRAK
Studi ini membahas pemikiran ekonomi Sayyid Qutb, dengan tujuan mempelajari pemikiran ekonomi Sayyid Quthb. Ini penting karena selama ini, Sayyid Qutb selalu diidentifikasi dengan tokoh-tokoh politik fundamentalis dan jauh dari ide-ide ekonomi. Faktanya, banyak ide ekonomi lahir dari Sayyid Qutb. Bahkan karyanya adalah Al-Adalah al-Ijtima'iyyah fi al-Islam, Ma'rakah al-Islam wa ar-Ra'sumaliyyah, Nahw al-Mujtma 'Islami, dan Tafsir fi Zilal al-Qur'an. berbicara banyak tentang ekonomi. Penelitian ini merupakan studi kualitatif berbasis perpustakaan (library research). Pendekatan yang digunakan adalah deskriptif kualitatif yang bertujuan untuk menggambarkan atau menggambarkan realitas yang ada atau apa yang terjadi atau realitas sebenarnya dari objek yang diteliti. Hasil penelitian menunjukkan bahwa pemikiran ekonomi Sayyid Qutb sangat relevan dalam konteks saat ini. Sayyid Qutb melihat bahwa komunitas itu terbagi menjadi dua, yaitu komunitas Islam dan komunitas jahiliyah. Di bidang keadilan sosial, Qutb mendekonstruksi konsep dan penerapan keadilan sosial melalui apa yang ia sebut "sosialisme".
\end{abstract}

Kata Kunci : Pemikiran, Ekonomi, Sayyid Qutb, Keadilan Sosial, dan Masyarakat Islam.

\section{DASAR PEMIKIRAN}

Perkembangan ekonomi Islam pada prinsipnya sudah dibangun dengan baik sejak masa Rasulullah SAW, Khulafa" Ar-Rasyidin. Selanjutnya dilanjutkan khilafah Umayyah, Abbasiyah, sampai ke Mughal di India. Setelah itu, perkembangan ekonomi Islam mengalami kemunduran. Perkembangan ekonomi Islam kembali bergeliat menancapkan eksistensinya sebagai salah satu bangunan ilmu yang kokoh sekitar tahun 1930-an ketika muncul kesadaran akan sebuah sistem ekonomi yang sesuai dengan karakter dan moralitas Islam. Ide ini digagas dan diinisiasi oleh beberapa pakar ekonomi Islam agar dapat menjawab berbagai permasalahan-permasalahan ekonomi kontemporer seperti mazhab Iqtishaduna, mainstream, dan kritis-alternatif. Ketiga mazhab ini yang mengisi ruang dialektika dan mempengaruhi pemikiran dan perkembangan ekonomi Islam sampai saat ini.

Sebenarnya sebelum berkembangnya mazhab ekonomi kontemporer telah muncul berbagai pemikiran ekonomi Islam dalam diri para pembaharu Islam seperti Jamaluddin al-Afghani, Muhammad Abduh, M. Rasyid Ridha, Muhammad Iqbal 
sampai kepada Sayyid Qutb. Akan tetapi, karena terlalu dominan pemikiran mereka dikaji dalam disiplin ilmu politik dan ketatanegaraan, sehingga seakan-akan pemikiran ekonomi tidak pernah lahir dan dikaji oleh mereka.

Tulisan berikut ini akan mengkaji pemikiran ekonomi Sayyid Qutb sebagai salah satu intelektual Islam terpenting abad ke-20. Walaupun Sayyid Qutb lebih banyak dilihat sebagai salah satu tokoh fundamentalis yang memimpin gerakan Ikhwan alMuslimin untuk menumbangkan kediktatoran rezim Gamal Abdul Nasher dan pemikiran-pemikiran politiknya banyak mengispirasi pemuda-pemuda di seluruh dunia muslim khususnya.

\section{PEMAHAMAN}

\section{BIOGRAFI SAYYID QUTB}

Sayyid Qutb Ibrahim Husayn Shadhili merupakan kritikus sastra, novelis, pejuangga, pemikir Islam Mesir, dan aktivis Islam Mesir paling terkenal pada abad ke20, bahkan popularitasnya melebihi pendiri Ikhwan al-Muslimin, Hasan al-Banna (19061949 M). Dilahirkan di desa Musha, Provinsi Asyut, 235 mil Selatan Kairo, di tepi barat Sungai Nil, pada 9 Oktober 1906 (Musallam, 1993: 64).

Ayahnya, Al-Haj Qutb Ibn Ibrahim adalah seorang petani kelas menengah yang berada dan menjadi anggota partai nasionalis. Ibunya bernama Fatimah adalah seorang muslimah relegius yang sangat memperhatikan pendidikan anaknya terutama dengan menanamkan rasa keberagamaan yang kuat dan cinta ilmu pengetahuan. Dia menghendaki agar semua anak-anaknya bisa menghafal al-Qur' an (Al-Khalidy, 1980: 59). Dilihat dari silsilah jalur ayahnya, dalam dirinya mengalir darah India karena kakek buyutnya yang keenam (jadduh al-sadis) yang bernama al-faqir Abdullah memang berasal dari India yang menetap di dataran Mesir saat setelah menunaikan ibadah haji (Munawir, 2011: 78).

Pendidikan awalnya ditangani oleh ayahnya sendiri. Lalu, pada usia enam tahun ia memulai pendidikan dasar di desanya. Karena ketajaman otaknua, ia berhasil menamatkan pendidikan dasar hanya empat tahun, dua tahun lebih cepat dari biasanya. Sayyid Qutb sudah menghafal al-Qurean sejak usia 10 tahun (Iqbal dan Nasution, 2010: 209). Pada usia 13 tahun, Sayyid Qutb berangkat di Kairo untuk meneruskan pendidikan di Madrasah Tsanawiyah dan setelah selesai baru melanjutkan ke Dar al-,Ulum. Pada 
masa ini Sayyid banyak mendapat pengaruh dari Abbas Mahmud al-,AAqad, seorang penulis Mesir terkenal yang cenderung pada pemikiran Barat (Shepard, 1992: 197). Setelah tamat dari Dar al-,Ulum, Sayyid Qutb diangkat sebagai Inspektur Kementerian Pendidikan. Dalam tugasnya ini ia menyempatkan diri mempelajari dan mengkaji berbagai disiplin ilmu pengetahuan dengan membaca buku-buku terjemahan bahasa asing ke bahasa Arab. Setelah itu ia pun menjabat sekretaris Thaha Husein, lalu kemudian sekretaris Al-,,Aqqad (Iqbal dan Nasution, 2010: 209).

Pada tahun 1948 Qutb menulis buku dengan judul Al-Adalah al-Ijtima'ijah fi alIslam (Keadilan Sosial dalam Islam). Setelah itu dia tinggal selama dua tahun di Amerika Serikat untuk mempelajari sistem dan organisasi pendidikan. Ketika tinggal di Amerika, Qutb memanfaatkan waktunya dengan baik untuk belajar banyak hal tentang Amerika dan Barat khususnya. Qutb menimba ilmu di tiga Perguruan Tinggi sekaligus, yakni; Wilson"es Teacheres College, di Washington, Greeley College di Colorado, dan Stanford University di California (Dahlan, dkk, 2005: 91).

Sepulang dari Amerika ia masuk menjadi anggota Al-Ikhwan al-Muslimin, dan kemudian menjadi teoritikus utama dari organisasi itu. Tahun 1951, pemerintah Mesir mengeluarkan larangan dan Pembubaran al-Ikhwan al-Muslimin (Jamhari, Ed), 2004: 165). Pada tahun 1955 sekitar bulan Mei, Qutb termasuk salah seorang pemimpin ikhwan muslimin yang ditahan setelah organisasi itu dilarang oleh presiden Nasser dengan tuduhan berkomplotan untuk menjatuhkan pemerintahan. Pada tanggal 13 Juli 1955, pengadilan rakyat menjatuhkan hukuman 15 tahun kepadanya. Ia ditahan di beberapa penjara Mesir hingga pertengahan tahun 1964. Pada tahun itu pula ia dibebaskan atas permintaan Abdul Salam Arif, presiden Irak yang mengadakan kunjungan ke Mesir.

Setelah keluar dari penjara, ia tetap aktif dalam gerakan al-Ikhwan dan terus menuangkan gagasan-gagasannya dalam buku dan media massa. Namun baru keluar dari penjara, ia ditahan kembali oleh Nasher dengan tuduhan bahwa ia mengkoordinasi anggota-anggota al-Ikhwan lainnya untuk menggulingkan Presiden Nasher dengan cara pemikiran revolusioner yang muncul dalam karyanya Ma'alim fi ath-Thariq (Musallam, 1993: 64). Pada 21 Agustus 1966, Ia bersama Abdul Fatah Ismail dan Muhammad Yusuf Hawwasy dinyatakan bersalah dan dihukum mati. Kemudian ia bersama dua orang temannya dihukum gantung pada 29 Agustus 1966. 
34 | Havis Aravik Pemikiran Ekonomi Sayyid Qutb

Sebagai seorang intelektual muslim yang mumpuni, Sayyid Qutb banyak melahirkan karya dalam berbagai disiplin ilmu. Adapun pemikiran Sayyid Qutb tentang ekonomi termaktub dalam karyanya Al-'Adalah al-Ijtima'iyyah fi al-Islam, Ma'rakah al-Islam wa ar-Ra'sumaliyyah, Nahw al-Mujtma' Islami, dan Tafsir fi Zilal al-Qur'an (Supriyadi, 2007: 104).

\section{PEMIKIAN SAYYID QUTB DALAM BIDANG EKONOMI}

Sayyid Qutb termasuk salah satu intelektual Muslim Modern yang pada pertengahan abad ke-20 yang menggunakan pemikiran Barat untuk melawan mereka sendiri dengan cara menemukan kembali kerangka pemikiran dan kehidupan yang didasarkan pada Islam, sekaligus membongkar sistem turunan kolonial (Progler, 2009: 388). Pemikirannya sangat berpengaruh terhadap politik dan budaya Arab, khususnya di kalangan pemuda (Akhavi, 1997: 378).

Sayyid Qutb menyatakan bahwa segala permasalahan kehidupan umat manusia telah diatur dalam Islam, tidak terkecuali masalah ekonomi. Adapun pemikiran ekonomi Sayyid Qutb akan diuraikan berikut ini :

\section{Konsep Masyarakat Islam}

Sayyid Qutb membedakan masyarakat manusia menjadi dua bagian, yaitu masyarakat Islam atau maju dan masyarakat jahiliyah atau terkebelakang. Masyarakat Islam menurut Qutb adalah masyarakat yang mengakui syariat Islam, yang berdiri diatas keesaan Allah yang mutlak dan ikhlas beribadah, baik perkataan maupun perbuatan, akidah maupun moral, tidak mengakui kekuasaan tertinggi kecuali kekuasaan Allah saja, dan memberikan kepada setiap orang kebebasan berkehendak dan memberikan kehendak untuk membebaskan diri dari semua macam penghambaan yang tidak benar.

Sedangkan masyarakat jahiliyah menurut Qutb adalah masyarakat yang tidak memeluk Islam sebagai agama, tidak memperhatikan ajarannya, sehingga masyarakat ini tidak berjalan sesuai dengan syariat, moral dan nilai-nilainya. Term "jahiliyah" Sayyid Qutb lebih maju dibandingkan dengan tokoh sebelumnya Abu al-A la alMaududi; jika al-Maududi hanya melihat jahiliyah di dalam dunia non-muslim, Qutb meyakini bahwa dunia muslim juga penuh dengan nilai-nilai busuk dan kebengisan jahiliyah. Jahiliyah bukan masa tertentu, ia adalah kondisi yang berulang-ulang setiap kali masyarakat menyeleweng dari jalan Islam, baik di masa lampau, sekarang, atau 
masa depan. Setiap usaha untuk menolak realitas dan kedaulatan Tuhan adalah jahili (Munawir, 2011: 75).

Baik penguasa maupun masyarakat yang melakukan kejahiliyaan dan tidak menjunjung tinggi ajaran Islam adalah kafir (tidak beriman dan tidak lagi muslim) (Kotob, 1995: 334). Setiap muslim mempunyai tugas untuk secara aktif memerangi masyarakat jahiliyah dengan tujuan untuk memperbaiki, dengan jalan jihad. Jihad adalah tugas suci. Tujuan dari jihad adalah mengembalikan kesatuan yang hilang antara manusia dan Tuhan (Orbach, 2012: 967).

Ciri khas jahiliyah adalah menolak otoritas ilahiah dan mendewakan manusia (Shepard, 2003: 524). Dengan kata lain, Jahiliyah memperlihatkan dominasi manusia atas manusia, dimana manusia tunduk kepada manusia ketimbang kepada Allah. Keadaan manusia seperti ini, sudah terjadi sejak lama, dari masa lalu, sekarang, dan akan datang. Dalam situasi jahiliyah ini, manusia hanya punya dua pilihan, melaksanakan hukum Allah secara keseluruhan atau melaksanakan hukum buatan manusia. Menjadi Islam atau jahiliyah. Jahiliyah ditunjukkan pula dengan adanya suatu sistem pemerintahan yang didasarkan atas nilai-nilai dan pranata-pranata buatan manusia, seperti demokrasi, monarkhi, atau kediktatoran; termasuk juga materialisme, komunisme, atau sistem filsafat lainnya yang tidak memberi tempat bagi Tuhan (Munawir, 2011: 87).

Dominasi budaya dan hegemoni Barat telah terjadi di mana-mana dan itu merupakan hasil dari jahiliyyah modern (Supriyadi, 2007: 104). Bahkan banyak masyarakat Islam yang terbenam dalam jahiliyyah (Orbach, 2012: 965). Untuk melawan jahiliyah ini, umat Islam harus melakukan taghyir al-'aqliyah (perubahan pola pikir) dimulai dari dasar-dasar kepercayaan, moral dan etikanya. Jihad harus dilakukan terhadap modernitas, dan tujuan akhir jihad adalah membangun kembali „kekuasaan Tuhan ${ }^{e e}$ di muka bumi, di mana syariah menjadi supremasi. Syariah dalam arti cara hidup menyeluruh yang telah digariskan Allah bagi kaum muslimin, mulai dari nilainilai keagamaan sampai adat kebiasaan dan norma sosial yang membentuk kehidupan manusia (Supriyadi, 2007: 104-105).

Qutb meyakini modernitas sebagai akar persoalan yang telah menjadikan kemanusiaan mengalami kebangkrutan dalam tataran nilai yang seharusnya dapat menumbuhkembangkan kehidupan manusia secara sehat. Hal ini terlihat jelas di dunia 
Barat yang tidak lagi mampu memberikan nilai-nilai kemanusiaan, bahkan juga tidak dapat memberikan pemahaman tentang hakikat eksistensi itu sendiri. Dalam perspektif Qutb, krisis kemanusiaan ini tidak bisa diselesaikan oleh ideologi-ideologi alternatif yang ada saat itu, baik marxisme maupun sosialisme. Hanya Islam satu-satunya ideologi yang bisa mengatasi ideologi-ideologi lain dan menyelesaikan persoalan kehidupan umat. Karena itu, supremasi Islam mutlak harus ditegakkan (A $\left.A^{e c} l a, 2010: 57\right)$. Seperti pada periode Madinah, dimana para muslim disediakan dengan undang-undang yang mereka butuhkan, negara punya kekuatan dan hukum diturunkan kepada masyarakat muslim, dan sistem didirikan untuk mereka yang memenuhi kebutuhan aktual masyarakat muslim (Akhavi, 1997: 381).

\section{KONSEP KEADILAN SOSIAL}

Keadilan sosial merupakan tampilan lain dari keadilan. Konsep mengenai keadilan telah dikemukakan oleh banyak ahli sesuai sudut pandang masing-masing, namun substansinya adalah mengenai sikap moral yang benar terkait dengan hubungan antar manusia dalam kehidupan bersama di dalam masyarakat atau negara (Sumadi, 2015: 857). John Rawls (1999: 3) dalam bukunya yang berjudul A Theory of Justice menegaskan bahwa keadilan adalah nilai yang paling utama dalam suatu pranata sosial dan bahwa hukum serta pranata sosial lain walaupun sedemikian efisien dan amat tertib haruslah direformasi atau dihilangkan apabila mereka tidak adil.

Menurut Eko Supriyadi Sayyid Qutb (2003: 116) menawarkan pembaharuan yang berkenaan dengan konsep dan penerapan keadilan sosial melalui apa yang disebutnya dengan "sosialisme" setelah berakhirnya kekuasaan Raja Faruq. Qutb melakukan dekonstruksi terhadap konsep keadilan sosial dan mengembangkan sosialisme sebagai media untuk keadilan sosial pada akhir dekade 1950-an dan awal 1960-an (Esposito, 2004: 287). Pemikiran Qutb tentang keadilan sosial dalam Islam dilatar belakangi oleh pandangannya bahwa prinsip keadilan sosial Barat itu didasarkan pada pandangan Barat yang sekular, di mana agama hanya bertugas untuk pendidikan kesadaran dan penyucian jiwa, sementara hukum-hukum temporal dan sekularlah yang bertugas menata masyarakat dan mengorganisasi kehidupan manusia.

Hasil dari pandangan Barat yang sekularis, Barat mengalami tiga kondisi, yakni : (1) lari dari Tuhan (Allah SWT), (2) terbukanya pintu-pintu produksi dan penemuan di 
berbagai aspek kehidupan, (3) kondisi penyusutan, kurus kering, dan pergantian. Kebebasan, demokrasi, dan maslahat telah menggerakkan perasaan seluruh bangsa Barat dan bala tentaranya aga menjajah bangsa lain untuk mengeruk kekayaan dan menghisap darahnya (Qutb, Azam, dan Al-,,Ulwan, 2009: 152-153).

Umat Islam tengah berada dalam lingkaran budaya yang berbeda-beda dalam kehidupan mereka, budaya-budaya yang tidak sepenuhnya Islam sebagaimana yang dicontohkan Nabi dan para sahabat. Untuk menjawab pertanyaan tersebut, Qutb memberikan resep yang telah dijalani oleh Nabi Muhammad SAW dan para sahabatnya, yaitu membentuk jamaah kecil yang berkomitmen kepada Allah dalam segala aspek kehidupannya, melakukan pemisahan emosional (uzla shuuriyya), kemudian membentuk generasi Qurani, dan akhirnya menyiapkan tatanan hukum sosial atau membina masyarakat.

Sayyid Qutb menegaskan bahwa keadilan merupakan pilar utama dalam negara Islam. Tidak boleh ada diskriminasi antar warga negara. Keadilan itu bukan hanya teoriteori mati, melainkan telah terbukti dan terlaksana dalam sejarah negara Islam (Qutb, 1994: 130-131). Keadilan sosial Islam adalah kemanusiaan yang meliputi seluruh segi dan dasar kehidupan manusia. Keadilan ini bukan semata-mata keadilan ekonomi saja, tetapi menyangkut pemikiran, kesadaran, dan sikap. Dengan kata lain, keadilan sosial Islam tidak hanya menyangkut nilai-nilai ekonomi dan material, tetapi juga menyangkut nilai spiritual dan moral (Chalil, 2009: 194). Lebih dari itu, Islam telah menyiapkan prinsip-prinsip dasar keadilan sosial dan mengukuhkan klaim orang miskin pada kekayaan orang kaya, menyediakan prinsip keadilan bagi kekuasaan dan uang, sehingga tidak ada perlunya untuk membius pemikiran manusia dan mengajak mereka untuk meninggalkan hak-hak bumi mereka untuk tujuan harapan mereka di akhirat.

Sayyid Qutb menyatakan asas Islam dalam menegakkan keadilan memiliki beberapa fondasi atau asas yang utama yaitu: Pertama, kebebasan jiwa yang mutlak. Islam menjamin kebebasan jiwa dengan kebebasan yang penuh, yang tidak hanya dinilai dari sisi maknawi atau sisi ekonomi semata, melainkan pada dua sisi itu secara keseluruhan. Islam membebaskan jiwa dari bentuk perbudakan, berupa kultus individu dan ketakutan terhadap kehidupan, rezeki dan kedudukan. Dalam Islam, orang yang dihormati adalah orang yang bertakwa, orang-orang yang beriman dan beramal saleh (QS. al-Hujurat [49]: 13). 


\section{Havis Aravik Pemikiran Ekonomi Sayyid Qutb}

Kedua, persamaan kemanusiaan yang sempurna. Dalam Islam, tidak ada kemuliaan bagi orang yang berasal dari keturunan bangsawan. Islam datang untuk menyatakan kesetaraan jenis manusia, baik asal maupun tempat berpulangnya, hak dan kewajibannya di hadapan undang-undang dan di hadapan Allah, baik di dunia maupun di akhirat. Tidak ada yang membedakan di antara manusia, kecuali amal saleh. Dan tidak ada kemuliaan kecuali bagi orang-orang yang bertakwa (Asnawi, 2013: 56).

Keadilan sosial dalam Islam, bertitik tolak dari suatu prinsip yang menggariskan bahwa kepemilikan terhadap harta kekayaan tidaklah bersifat mutlak. Kepemilikan mutlak adalah monopoli dari Pencipta alam semesta dengan segala isinya yaitu Allah. Manusia hanyalah pemilik dalam makna yang nisbi. Oleh karena itu, setiap individu muslim bertanggungjawab kelak di akhirat tentang asal-usul harta miliknya dan kemana harta itu dibelanjakan dan dipergunakannya.

Menurut Asnawi, Sayyid Quthb dalam Fi Zilal al-Qur`an menyatakan bahwa manusia diciptakan di dunia ini sebagai khalifah yang memiliki nilai solidaritas, dan menjadi penolong terhadap yang lain. Bukan atas kaidah kebebasan mutlak seperti yang dikatakan Marxisme, tetapi atas dasar pemilikan pribadi yang terikat. Qutb sangat mengkritik konsep marxisme sebagai faham marxisme yang dari sudut pandang teori, dibangun di atas kebodohan mendalam terhadap jiwa manusia, tabiat dan sejarahnyaterlebih lagi kebodohan mendalam terhadap hakekat alam semesta, penjelasan alam dan kehidupan. Faham ini mempersepsikan seluruh gerakan sejarah muncul akibat adanya perubahan alat-alat produksi. Ia mengabaikan faktor terpenting manusia yang membedakan sejarahnya dengan binatang (Qutb, Azam, dan Al-,,Ulwan, 2009: 66).

Menurut Sayyid Qutb sebagaimana dikutip Asnawi (2013: 57-60) pesan-pesan dalam al-Qurean menyiratkan secara tegas bahwa pelaksanaan ekonomi harus mengikuti nilai-nilai kebaikan dan keadilan. Nilai-nilai tersebut menjadi contoh konkret kehidupan sosial yang diinginkan Islam, seperti akan diuraikan sebagai berikut :

Pertama, Perintah Allah kepada manusia untuk berbuat kebajikan serta melaksanakan ibadah zakat yang merupakan wujud kepedulian sosial (QS. al-Anbiya" [21]: 73). Zakat yang merupakan simbol dari fiscal policy dalam Islam dan merupakan sarana pertumbuhan ekonomi sekaligus mekanisme yang bersifat built in untuk tujuan pemerataan penghasilan dan kekayaan. Tidak ada satu pun jenis harta yang lepas dari 
kewajiban zakat, kapan pun waktunya. Sedangkan ukurannya diterangkan dalam AsSunnah sesuai dengan jenis hartanya (Qutb, 2000: 255).

Kedua, Perintah beribadah kepada Allah shalat dan mengeluarkan zakat secara ikhlas (al-Bayyinah [98]: 5). Zakat merupakan istilah al-Qurean yang menandakan kewajiban khusus memberikan sebagian kekayaan individu dan harta untuk amal. Secara harfiah zakat berasal dari akar kata dalam bahasa Arab yang berarti "memurnikan" dan "menumbuhkan". Zakat berfungsi meliputi bidang moral, sosial, dan ekonomi. Dalam bidang moral, zakat mengikis ketamakan dan keserakahan hati si kaya. Adapun dalam bidang sosial, zakat berfungsi untuk menghapuskan kemiskinan dari masyarakat. Di bidang ekonomi, zakat mencegah penumpukan kekayaan di tangan sebagian kecil manusia dan merupakan sumbangan wajib kaum musliminin untuk perbendaharaan negara (Aravik, 2017: )

Menurut Qutb (1994: 111) keengganan menunaikan zakat dikalangan orangorang kaya akan bermuara pada kebencian manusia di dunia, dan kerusakan masyarakat karena ulah yang tidak mau menafkahkan sebagian harta, yang selanjutnya terus pada fitnah, kedengkian dan kelemahan.

Ketiga, Aturan dalam perdagangan dengan mekanisme yang telah ditetapkan Allah, yaitu melakukan timbangan dan takaran yang benar ( QS. al-A,,raf []: 85). Kecurangan dalam menakar dan menimbang mendapatkan perhatian khusus dalam alQurean, karena praktik seperti ini telah merampas hak orang lain. Selain itu, praktik seperti ini juga menimbulkan dampak yang sangat buruk dalam dunia perdagangan yaitu timbulnya ketidakpercayaan pembeli terhadap para pedagang yang curang. Oleh karena itu, pedagang yang curang pada saat menakar dan menimbang mendapat ancaman siksa yang sangat pedih di akhirat (QS. Al-Muthafiffin [83]: 1-6).

Keempat, tidak menumpuk-numpuk harta dan kekayaan (QS. Al-Humazah []: 14). Hal ini penting karena harta atau kekayaan merupakan pemberian dari Allah kepada manusia untuk dapat dimanfaatkan dengan sebaik-baiknya guna kesejahteraan seluruh umat manusia secara ekonomi, sesuai dengan kehendak Allah SWT (Akbar, 2012: 126). Kelima, Larangan memakan, melakukan dan mempraktekkan riba. (Al-Baqarah [2]: 275-276). Hal ini karena kebebasan ekonomi dalam Islam terbatas, disebabkan haramnya beberapa aktivitas ekonomi yang mengandung pemerasan, monopoli atau riba (QS. An-Nisa" [4]: 29). Setidaknya ada beberapa alasan mengenai pengharaman riba, 


\section{0 | Havis Aravik Pemikiran Ekonomi Sayyid Qutb}

yakni : (a). Riba adalah mengambil harta orang lain tanpa nilai imbalan apa pun. Padahal, menurut Rasulullah SAW harta seseorang adalah seharam darahnya bagi orang lain. (b). Riba dilarang karena menghalangi manusia untuk terlibat dalam usaha yang aktif. (c). Kontrak riba adalah media yang digunakan orang untuk mengambil kelebihan dari modal. Perbuatan ini haram dan bertentangan dengan keadilan dan persamaan. (d). Kontrak riba memunculkan hubungan yang tegang di antara sesama manusia. (e). Keharaman riba dibuktikan dengan ayat al-Qurean, dan seseorang tidak perlu tahu alasan pengharamannya (QS. [3]: 39, [4]: 160-161, Ali Imran [3]: 130, dan Al-Baqarah [2]: 278-279) (Aravik, 2016: ).

Keenam, Kewajiban untuk melawan penindasan ekonomi, fisik dan membela kalangan masyarakat lemah dari pihak-pihak yang zalim (QS. al-Nisa" []: 75). Sayyid Qutb menyatakan bahwa Islam sangat menentang segala bentuk penindasan ekonomi, fisik dan sangat membela hak-hak kelompok yang terzalimi. Islam datang pada suatu zaman yang penuh dengan kezaliman, penindasan, ketidakadilan, dan ketmpangan ekonomi, sehingga masyarakat di golongkan ke dalam kelompok-kelompok kecil berbasis suku dan kabilah. Struktur sosial seperti inilah yang kemudian memunculkan stratifikasi sosial yang sangat kuat (Harahap, dkk, 2015: 71).

Islam bertujuan untuk membangun struktur sosial di mana setiap individu di satukan oleh hubungan persaudaran dan rasa sayang sebagaimana satu keluarga yang diciptakan oleh Allah dari sepasang manusia. Persaudaraan ini bersifat universal, tidak terikat ruang dan batas-batas geografis tertentu serta mencakup semua umat manusia bukan hanya keluarga, suku, atau ras tertentu (QS. al-A"eraf [7]: 158) (Harahap, dkk, 2015: 72). Islam mengajarkan setiap majikan untuk membuang sifat keras hati dan kejam kepada buruh. Kebutuhan psikologisnya adalah kebutuhan untuk diperhatikan, dihargai serta dianggap penting. Penyegeraan pembayaran upah adalah pemenuhan kebutuhan ini. Buruh akan merasa jerih payahnya dihargai dan kedudukannya dalam masyarakat diperhitungkan. Sedangkan pemenuhan kebutuhan materialnya dimaksudkan dengan pembayaran upah yang layak (Qutb, 1995: 106-107). Untuk itu, salah satu ajaran Islam mengenai buruh adalah pemberian beban kerja tidak melebihi kemampuan buruh. Al-Qurean melalui kisah Nabi Musa, a.s. yang bekerja di rumah Nabi Syueaib, a.s. (QS. al-Qashash [28]: 27) menunjukkan dalam pemberian kerja 
majikan tidak boleh mengabaikan prinsip-prinsip kemanusiaan, keadilan, dan kesaksamaan (Harahap, dkk, 2015: 78).

Ketujuh, Keadaan mereka yang tertindas dan miskin tetap akan tertindas dan miskin, bila mereka sendiri tidak bangkit melemparkan belenggu yang dililitkan kaum penindas atas leher mereka (QS. a1-Ra,,du [13]: 11). Untuk itu, Islam mengharuskan manusia untuk bekerja (QS. At-Taubah [9]: 105, Al-An"am [6]: 135, Hud [11]: 36, 121, dan Az-Zumar [39]: 39), agar dapat keluar dari lingkaran setan kemiskinan dan dengan bekerja setiap orang dapat memperoleh upah (Qs. At-Thalaq [65]: 6, Az-Zukhruf [43]: 32).

\section{SIMPULAN}

Berdasarkan paparan di atas dapat disimpulkan bahwa Sayyid Qutb termasuk salah satu intelektual Muslim Modern yang pada pertengahan abad ke-20 yang menggunakan pemikiran Barat untuk melawan mereka sendiri. Dalam bidang ekonomi, pemikiran Sayyid Qutb dapat ditemukan dalam karya-karyanya seperti Al-'Adalah alIjtima'iyyah fi al-Islam, Ma'rakah al-Islam wa ar-Ra'sumaliyyah, Nahw al-Mujtma' Islami, dan Tafsir fi Zilal al-Qur'an. Sayyid Qutb melihat bahwa masyarakat terbagi menjadi dua, yakni masyarakat Islam atau maju dan masyarakat jahiliyah atau terkebelakang. Kehancuran Barat dan umat Islam karena menjadi masyarakat jahiliyah. Dalam bidang keadilan sosial, Sayyid Qutb sampai pada kesimpulan bahwa kepemilikan terhadap harta kekayaan tidaklah bersifat mutlak. Kepemilikan mutlak adalah monopoli dari Pencipta alam semesta dengan segala isinya yaitu Allah. Manusia hanyalah pemilik dalam makna yang nisbi. Oleh karena itu, setiap individu muslim bertanggungjawab kelak di akhirat tentang asal-usul harta miliknya dan kemana harta itu dibelanjakan dan dipergunakannya.

\section{Daftar Pustaka}

\section{Buku}

Al-Khalidy, Abd al-Salah Muhammad, 1980. Sayyid Quthb al-Syahid al-Hayy, Beirut: Muassassah al-Risalah.

Aravik, Havis, 2016. Ekonomi Islam; Teori, Konsep dan Aplikasi Serta Pemikiran Para Tokoh Ekonomi Islam dari Mulai Abu Ubaid Sampai Al-Maududi, Malang: Empat Dua. 
2017. Sejarah Pemikiran Ekonomi Islam Kontemporer, Jakarta: Kencana Prenada Media Group.

Chalil, Zaki Fuad, 2009. Pemerataan Distribusi Kekayaan dalam Ekonomi Islam, Jakarta: Erlangga.

Dahlan, Abdul Aziz dkk, 2005. Ensiklopedi Islam, Jakarta: Ichtiar Van Hoeve.

Esposito, John L., 2004. Islam: The Straight Path, $3^{\text {rd }}$ Edition, Terj. Arif Maftuhin, Jakarta: Paramadina.

Harahap, Isnaini, dkk, 2015. Hadis-Hadis Ekonomi, Jakarta: Kencana Prenada Media Group.

Iqbal, Muhammad dan Amin Husein Nasution, 2010. Pemikiran Politik Islam; Dari Klasik Hingga Indonesia Kontemporer, Jakarta: Kencana Prenada Media Group.

Jamhari, (Ed), 2004. Gerakan Salafi Radikal di Indonesia, Jakarta: PT. Raja Grafindo Persada.

Qutb, Sayyid, 1995. al- 'Adalah al-Ijtima'iyah Fi al-Islam, Kairo: Dar al-Shuruq. Insani Press. , 2000. Tafsir Fi Zhilalil Qur"an, Pen. As"ad Yasin dkk, Jakarta: Gema , 1994. Al- 'Adalah al-Ijtima'iyah fil-Islam, terj. Afif Mohammad, Bandung : Pustaka.

Abdullah Azam, Syaikh Sulamian bin Nashir al-,Ulwan, 2009. AlMustaqbal Lihadza Ad-Din Al-Islam wa Mustaqbal Al-Basyariyyah Ala Inna Nasharralah Qarib, Terj. Abu Nadidah Humaero, dan Abu Ja"efar Al-Indunisy, Solo: Media Islamika.

Rawls, J., 1999. A Theory of Justice, Massachusets: Harvard University.

Supriyadi, Dedi, 2007. Perbandingan Fiqh Siyasah; Konsep, Aliran, dan Tokoh-Tokoh Politik Islam, Bandung: CV. Pustaka Setia.

Supriyadi, Eko, 2003. Sosialisme Islam Pemikiran Ali Syari'ati, Yogyakarta: Pustaka Pelajar.

Zamzam, Fakhry, dan Havis Aravik, 2016. Manajemen SDM Berbasis Syariah, Bogor: CV. RWTC Success

\section{Jurnal}

A la, Abu, 2010. "Sikap Muslim Fundamentalis Indonesia terhadap NKRI Antara Penolakan dan Penerimaan Setengah Hati", Jurnal Unisia, Vol. xxxiii No. 73 Juli 2010.

Akbar, Ali, 2012. "Konsep Kepemilikan dalam Islam”, Jurnal Ushuluddin, Vol. XVIII No. 2, Juli 2012.

Akhavi, Shahrough, 1997. "The Dialectic In Contemporary Egyptian Social Thought: The Scripturalist and Modernist Discourses of Sayyid Qutb And Hasan Hanafi", Int. J. Middle East Stud. 29 (1997).

Asnawi, 2013. "Konsep Sosialisme Islam Menurut Sayid Quthb”, Jurnal Substantia, Vol. 15, No. 1, April 2013. 
Kotob, Sana Abed, 1995. "The Accommodationists Speak: Goals And Strategies Of The Muslim Brotherhood of Egypt", Int. J. Middle East Stud. 27 (1995).

Munawir, M. Fajrul, 2011. "Relevansi Pemikiran Sayyid Qutb Tentang Tafsir Jahiliyah Bagi Dakwah dan Pengembangan Masyarakat Islam Kontemporer", Jurnal Dakwah, Vol. XI, No. 1 Tahun 2011.

Musallam, Adnan, 1993. "Sayyid Qutb"s View of Islam, Society and Militancy", Journal of South Asian and Middle Eastrn Studies, Vol. Jou, No. 1, Fall 1993.

Orbach, Danny, 2012. "Tyrannicide in Radical Islam: The Case of Sayyid Qutb and Abd al-Salam Faraj”, Middle Eastern Studies, Vol. 48, No. 6, November 2012.

Progler, Yusef, 2009. “The Westernization of Islamic Education”, Jurnal Insania, Vol. 14, No. 2, Mei-Agustus 2009.

Shepard, William E., 2003. "Sayyid Qutb"s Doctrine of Jahiliyya", Int. J. Middle East Stud. 35 (2003).

Shepard, William, 1992. "The Development of the Thought of Sayyid Qutb as Reflected in Earlier and Later Editions of Social Justice in Islam", Die Welt des Islams, New Series, Bd. 32, Nr. 2 (1992).

Sumadi, Ahmad Fadlil, 2015. "Hukum dan Keadilan Sosial dalam Perspektif Hukum Ketatanegaraan”, Jurnal Konstitusi, Volume 12, Nomor 4, Desember 2015. 